\title{
Guest editorial: JCAL access to support teaching research methods
}

\author{
Nancy Law \\ University of Hong Kong \\ Teaching research methods courses to postgraduate students in education is always a \\ challenge. Students generally see the problem of research design to be one of \\ locating the best method and instrument to use to answer a question that they have. \\ One of the most difficult points to drive home is that given a research question, one \\ may still be framing it rather differently based on different theoretical perspectives \\ and the kind of outcomes that one is interested in. One way to tackle this problem is \\ to precede the introduction of detail research design issues for different \\ methodology by getting students to examine a number of high quality and yet \\ different papers addressing similar issues from different perspectives, arriving at \\ different and useful outcomes.
}

My recent attempt to use this approach in my research methods course was very much facilitated by the online access to JCAL through Synergy. The value of JCAL is that it does not subscribe or confine itself to only one type of theoretical orientation. so it was easy for me to locate pairs of papers addressing similar problems from different perspectives and thus using different methods. My students are all full time education professionals and would not have the opportunity to visit the library on a day-to-day basis. Without the online access, it would be difficult to require them to complete the discussion and critique of the papers within a short period of time that the course timetable requires them to.

One example of a pair of papers that I used is the following:

- Virtual reality and hypermedia in learning to use a turning lathe

(JCAL, 17, 2, 142-155)

- Visualisation and animation in a CAL package

(JCAL, 17, 2, 206-216)

The questions that I asked students to consider for each paper were:

- what is the purpose of the research?

- what are the research questions addressed by this research?

- what kinds of literature would need to be reviewed and for what purpose?

- what method(s) of research should be employed?

- what kind of research would you categorise this to be?

The first paper asks whether novices \& experts benefit from using a virtual lathe and what may be the best arrangement. It uses a positivistic and quantitative approach to the research with pre- and post-tests to address the questions.

The second paper explores the role of visual representation and issues of instructional design and uses phenomenographic case studies with multi-method data collection to address the questions.

Both papers, however, research effective ways of using multimedia in education. Their access through Synergy made learning under this approach a feasible task for

Correspondence: Professor Nancy Law, Department of Curriculum Studies, The University of Hong 
my students.

Short code: JCA

Title: Journal of Computer Assisted Learning

ISSN: 0266-4909

Created by: Robert Lewis

Word version: 7.0a

BEES version: Version 2.39

Email proofs to: xxx@xxx

Copyright: (C) 2003 Blackwell Science

Volume: 19 (Issue: 1)

Cover year: 2003 (Cover month: March)

Article no.: JCAed19-1

DOI: 10.1046/j.0266-4909.2002.00019.x

Article type: ED (Editorial)

Figures: 0; Tables: 0; Equations: 0; References: 0; Words: 506; First Page: 1; Last Page: 1

Short title running head: Editorial

Authors running head: Editorial 